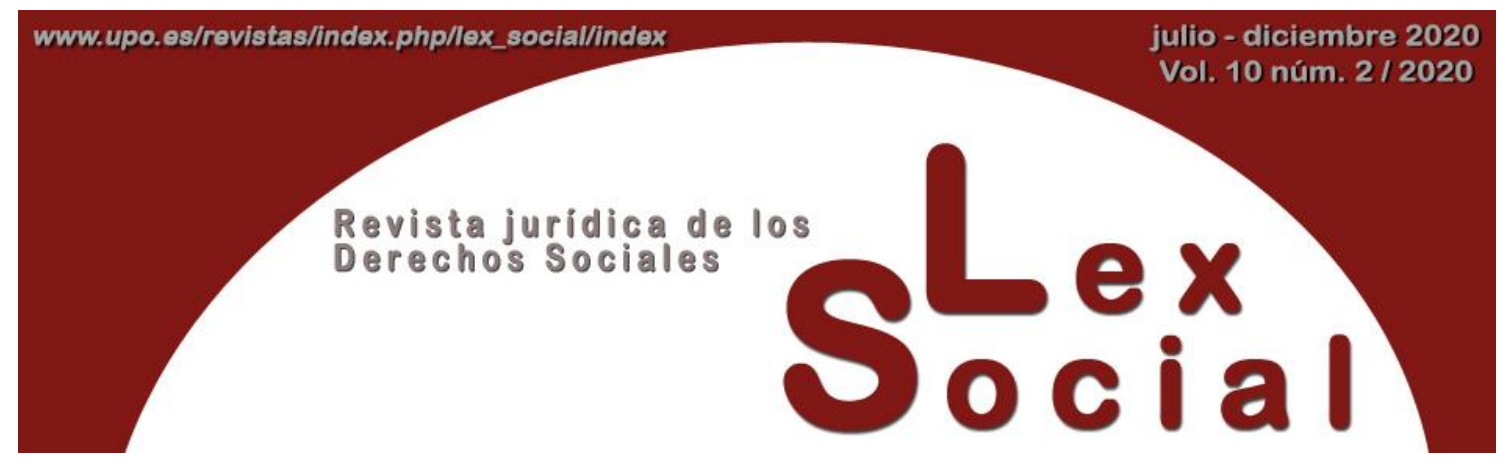

\title{
RECENSIÓN
}

\section{Colomer Viadel, Antonio, El laborismo en España. Mi experiencia personal, Alicante, Publicacions de la Universitat d'Alacant, 2019}

\author{
Dr. LUIS JIMENA QUESADA \\ Catedrático de Derecho Constitucional \\ Universidad de Valencia
}

El Profesor Colomer Viadel, Catedrático de Derecho Constitucional de la Universidad Politécnica de Valencia, nos ofrece una nueva monografía, sólida y de lectura imprescindible para acercarnos, si se me permite la expresión parafraseando a Javier Cercas, a la anatomía de unos instantes únicos de la transición española a la democracia, en los que el propio autor fue protagonista compartiendo ahora su rica vivencia personal.

En efecto, el Doctor Colomer nos transmite un legado inédito acerca del pensamiento laborista y su aparición durante la transición democrática. Cierto es que el laborismo español no fraguó en ese período crucial de la reciente historia política y constitucional española que condujo a la adopción de nuestra vigente Carta Magna. Es verdad asimismo que el laborismo español presenta elementos no equiparables a su homólogo británico (al no vincularse el nuestro al sindicalismo).

Ahora bien, tras atenta lectura del libro reseñado, no resulta desacertado esgrimir que la falta de éxito de la propuesta laborista en aquel momento (acaso por unos tintes utópicos que no consiguieron el apego suscitado por el clásico y centenario socialismo -pese a las pequeñas facciones presentes en este y que hicieron emerger divergencias internas a la hora de decidir incluso la integración de la ponencia constitucional-) en modo alguno faculta para considerarla obsoleta en la actualidad, tanto más cuanto que la confluencia de los partidos mayoritarios de centro-izquierda y centro-derecha en las últimas décadas (especialmente por el peso determinante de las políticas económicas impulsadas desde la Unión Europea) fue objeto de crítica antes y después de la crisis financiera iniciada en 2008. 
Concretamente, con anterioridad a dicha crisis y todavía con el dominio del bipartidismo clásico en el tablero político (baste rememorar la crítica a los gobiernos socialistas a la sazón como que practicarían políticas de derecha en lo económico, o incluso la "reforma exprés" del artículo 135 de la Constitución española negociada y aprobada en 2011 por PSOE y PP de espaldas a las demás fuerzas de la minoría parlamentaria), recordemos la idea de la "tercera vía" evocada desde la socialdemocracia (como ilustró la marca del "nuevo laborismo"/“"new labour" británico liderado por Tony Blair y Gordon Brown desde mediados de los años 1990 y la década de 2000); y, con posterioridad a ella, no es menester ser un lince del análisis político para comprobar que la pérdida de ese predominio de los partidos mayoritarios y la irrupción de los "emergentes" se ha plasmado en opciones populistas (también en la extrema izquierda) que han producido un desencanto hacia quienes aparentemente promovían desde los movimientos "indignados" un sincero nuevo contrato social.

En estas coordenadas, la monografía del Profesor Colomer se hace merecidamente acreedora de un hueco para una reflexión orientada a la acción, máxime en el trágico momento actual provocado por el COVID-19 (temática candente de debate y de combate), que revela no solo una crisis sanitaria y humanitaria, sino también económica, social y, a buen seguro, más ampliamente cultural que pone en jaque los valores y pilares del Estado de Derecho, la democracia y los derechos humanos (también en su dimensión social) en los que se sustenta igualmente la Europa social y un constitucionalismo social mundializado y multinivel.

Con estos mimbres, la obra se estructura coherentemente en tres capítulos que se ocupan de manera sucesiva de los antecedentes del laborismo español por referencia al partido sindicalista, del registro y actuación del partido laborista como asociación política durante la transición hacia la democracia, y de la experiencia personal del autor. Se pone colofón al libro con unos nada despreciables anexos, precedidos por el "Himno laborista" (p. 60), entre los que se incluyen cartas dirigidas a y/o publicadas en la prensa en las que se articulaba el pensamiento y las propuestas laboristas del Profesor Colomer Viadel en torno a la defensa de la propiedad comunal (Anexo I), o la pretensión del partido laborista (y de la Federación Laborista en la que se integraba) de configurarse como "una solución de izquierda para España" (Anexo II), además de la transcripción del manifiesto laborista (Anexo III) en donde se recogen las razones del nacimiento del partido como partido de izquierda y de respuesta a la realidad de aquel momento (1977), sus ideas sobre España y la posición de ella en el mundo, la sociedad a la que aspiraba el laborismo, los condicionantes (económicos, sociales y políticos) de la España de entonces, el diagnóstico sobre la problemática española y las "recetas" para solucionarla en sus diversas facetas (económica, social y política).

$* * * * *$

Con semejante aproximación, en el capítulo primero ("Introducción y antecedentes"), Antonio Colomer explica que, pese a la inexistencia en nuestro país de una construcción 
similar al laborismo británico y su íntima relación con los sindicatos, ello no ha sido óbice para que, en algunos momentos de nuestra historia a partir de la primera mitad del siglo $\mathrm{XX}$, tuvieran lugar iniciativas con etiqueta "laborista" $\mathrm{y}$, desde posiciones sindicales, planteamientos más o menos posibilistas y políticos impregnados de cierto radicalismo tanto desde la izquierda como desde la derecha.

Entre esos antecedentes, el autor nos presenta unos interesantes intentos políticos de impacto electoral y parlamentario llevados a cabo por grupos próximos y originarios de posiciones libertarias y anarcosindicalistas en el contexto de las elecciones municipales de 1917 en las que se implicó la Federación de Sociedades de Resistencia Solidaria Obrera o la Federación de Municipios Libres. Más tarde, desde una cierta alianza entre anarquismo y federalismo republicano, aglutinada en torno al Partido Social Ibérico (vinculado al diario La Tierra), las elecciones de 1933 constituyeron un laboratorio político de indudable interés para comprender las tensiones y escisiones (en el seno de ese germen del laborismo) derivadas de posturas abstencionistas frente a otras más comprometidas con la implicación en la toma de decisiones políticas y parlamentarias (y, consiguientemente, en la elaboración de una legislación social y progresista) y las acusaciones y reproches de favorecer a las derechas. En esa misma coyuntura, figura un intento frustrado de Eduardo Aunós de fundar en abril de 1930 un partido laborista, sin vinculación con el laborismo inglés y próximo al programa corporativista propio de la dictadura de Primo de Rivera; un partido que careció de trascendencia.

Unos años más tarde, tras tentativas poco exitosas (algunas de ellas tendentes a cambiar el rumbo de la CNT) de crear el Partido Libertario y un Partido Obrero del Trabajo, otra iniciativa de interés para constituir un partido laborista en España se produjo en 1945 mediante una amalgama de diversa procedencia (del ala más socializante de Falange, de antiguos miembros de la CNT, del Partido Socialista y del Partido Sindicalista) que tuvo cierta implantación en algunas ciudades y provincias (Madrid, Galicia, Valencia, Cataluña o Asturias).

Sin embargo, la iniciativa de mayor implantación y peso ideológico en la que pone el foco de atención el Profesor Colomer para comprender los antecedentes del laborismo en España es la impulsada por Ángel Pestaña para fundar el Partido Sindicalista en 1934. Su fundador, aunque hubiera sido secretario general de la CNT y conocedor sobre el terreno de la Unión Soviética (a donde había viajado para participar en 1920 en el Congreso Internacional de la Sindical Roja y en el II Congreso de la Internacional Comunista), entendía necesario actuar en la política con independencia de los sindicatos, sin por ello dejar de representar los intereses obreros en el Parlamento. Así las cosas, tras su percepción crítica sobe las miserias que había observado en la URSS, ello le condujo a un alejamiento del marxismo y un cierto acercamiento a las tesis del laborismo inglés.

A este respecto, Antonio Colomer trae a la memoria como anécdota la refundación del Partido Sindicalista en los albores de la transición democrática (en 1976) por parte de Ceferino Maestu (uno de los fundadores de Comisiones Obreras que procedía del espíritu de Falange Auténtica, contraria al régimen franquista), y que fue operativo hasta 1985 
junto a su periódico Sindicalismo. Y, con carácter previo, recalca el Doctor Colomer los debates aperturistas entre Torcuato Fernández Miranda y Manuel Fraga frente a los sectores más conservadores del régimen franquista (del "búnker") para la eliminación de la censura previa y la puesta en marcha del asociacionismo político (camuflado o disfrazado de asociacionismo cultural inicialmente), debate que vino favorecido en los últimos años del franquismo por la apertura económica, el turismo y, sobre todo, el deseo de integración en las Comunidades Europeas.

Otro dato curioso y nada desdeñable que comparte con nosotros el autor tiene que ver con ciertas iniciativas de apertura democrática favorecidas desde el Instituto de Estudios Políticos (fundado en 1939 tras la Guerra Civil, refundado como Centro de Estudios Constitucionales en 1977 y denominado desde 1997 como Centro de Estudios Políticos Constitucionales) ya a mediados de los años 1960, a modo de "cierto oasis de pluralismo" en el que pudo tener su espacio el Profesor Tierno Galván pese a su trayectoria socialista y en el que tuvo la fortuna de colaborar académicamente (como profesor o como director de números monográficos de la Revista de Estudios Políticos o del Boletín del IEP) el propio Profesor Colomer Viadel durante un dilatado período (entre 1966 y 1978).

$$
* * * * *
$$

Por su lado, el capítulo segundo ("La regulación de la participación política entre el final del Franquismo y el inicio de la Transición”) pone el acento en el registro del Partido Laborista como asociación política. Como presupuestos obvios, se mencionan dos elementos normativos: el primero de ellos, bajo la presión de la revolución de "Los Claveles" en nuestra vecina Portugal en abril de 1974, la aprobación por el último Gobierno en vida de Franco, presidido por Carlos Arias Navarro, del Decreto-ley 7/1974, de 21 de diciembre, que aprobaba el estatuto jurídico del derecho de asociación política; y el segundo, con el primer Gobierno de Adolfo Suárez ya con el Rey Juan Carlos como Jefe del Estado, la Ley 21/1976, de 14 de junio, sobre el derecho de asociación política.

En particular, la asociación política denominada "Partido Laborista" quedó inscrita el 4 de octubre de 1976 en el Registro de Asociaciones Políticas del entonces Ministerio de la Gobernación. Sin duda, lo más sustancial de la documentación que se acompañó con la solicitud de registro fue el propio "Manifiesto Laborista", que incluía una Memoria -en palabras del autor- con una importante declaración "casi libertaria" ("Toda persona humana tiene derecho a decidir, en forma eficaz, en todos los asuntos que le afecten o conciernan. Por consiguiente, más que procurar el alcance del Poder, la Asociación Política Laborista denunciará las concentraciones de poder, procurará encontrar soluciones para su distribución y coadyuvará a que, cada persona, asuma el poder que le corresponda") y acorde con la primera afirmación del Manifiesto (que preconizaba la Autogestión en su sentido más amplio).

Sin perjuicio de ello, el nuevo Partido Laborista no cerró sus opciones estratégicas, abriendo contactos y entablando conversaciones con la "Taula de Forces Polítiques i Socials del País Valencià" y su posible ingreso junto a otras fuerzas de oposición, así 
como con el Partido Socialdemócrata Español y el PSOE histórico. En el plano operativo, ya durante ese mismo año 1976, el Doctor Colomer menciona las propuestas de la Comisión Ejecutiva del Partido Laborista que pasaban por exigir, además de un sistema electoral imparcial, la desaparición de las facultades gubernativas discrecionales (sic: arbitrarias) con relación al ejercicio de las libertades de expresión, reunión y manifestación; la supresión de los juzgados y tribunales de orden público y la derogación total del Decreto-ley de prevención del terrorismo; el reconocimiento del derecho a constituir partidos políticos sin exclusiones; el acceso en condiciones de igualdad a los medios de comunicación social, espacios publicitarios y locales para las actividades públicas de los partidos políticos; la no utilización de los fondos públicos y del aparato político-administrativo del Movimiento a favor de opciones "privilegiadas", y el restablecimiento de la facultad de las futuras Cortes de ser el juez último de la validez de las actas de sus miembros.

Con respecto a estos avatares políticos del período de transición, el Profesor Colomer destaca el doble hito histórico con el que concluía el año 1976, primero con la aprobación de la Ley para la Reforma Política el 18 de noviembre y su sometimiento a referéndum nacional al mes siguiente el 15 de diciembre. El Partido Laborista dejó libertad de voto a sus asociados, oponiendo objeciones al proyecto sometido a referéndum (entre ellas, la oposición a la potestad del Rey de designar Senadores; la disconformidad con reservar al Gobierno y al Congreso de los Diputados la iniciativa para la reforma constitucional, postulando la iniciativa popular respaldada por un cierto número de ciudadanos de acuerdo con el principio de autogestión y de autogobierno de las colectividades; la no conformidad con los mecanismos correctores de la representación proporcional para evitar falseamientos escandalosos; y el establecimiento de una más clara correlación entre el principio de mayoría parlamentaria y el nombramiento de cada Gobierno).

Sea como fuere, el Doctor Colomer Viadel hace notar que la celebración de ese referéndum constituía un escalón positivo más hacia la democratización del país y que el laborismo no renunciaba a seguir apostando por la solución de otros problemas vitales que deberían someterse a consulta (y no se hizo), como la reforma fiscal, las medidas prácticas para la escolarización total, la lucha contra la especulación o la descentralización efectiva. Pero, por encima de todo, subraya la propuesta más relevante, consistente en postular la apertura de un proceso constituyente para reconocer al pueblo como auténtico soberano, que se explicitó en una declaración de prensa de 19 de septiembre de 1976 a raíz de las conversaciones del Partido Laborista con el Partido Socialista Democrático Español.

De hecho, observa igualmente el Profesor Colomer que esa vocación federativa del laborismo se mantuvo incluso en la participación electoral del 15 de junio de 1977. Así, en el panorama de "sopa de letras" generada por la multiplicación de propuestas partidistas que aspiraban a consolidar los designios democráticos del pueblo español, el Partido Laborista constituyó para concurrir a esas primeras elecciones democráticas la Federación Laborista (en documento fechado el 3 de mayo de 1977 y registrado ante la Junta Electoral Central, suscrito por el propio Antonio Colomer como Secretario General 
del Partido Laborista junto con los representantes del partido Nueva Izquierda Nacional y del Partido Reformista Independiente). Como anécdota, recuerda asimismo nuestro autor (que encabezó por Valencia la candidatura a Diputados del Congreso por parte de la Federación Laborista en esas elecciones de 15 de junio de 1977) que hubo de solicitar rectificación a la Junta Electoral Central para advertirle que la denominación de la Federación era "laborista", no "laboralista".

El caso es que esa tendencia federalista del Partido Laborista prosiguió tras esas primeras elecciones democráticas, tanto por la voluntad ideológica de sus integrantes como por la conciencia acerca de la necesidad de movilizar recursos financieros que exige el sistema electoral. Con tal filosofía, el Profesor Colomer apela a los esfuerzos por aglutinar a la socialdemocracia de cara a una coalición electoral para concurrir en las primeras elecciones democráticas tras la aprobación de la Constitución de 1978; entre esos esfuerzos, la redacción por él mismo de un Manifiesto de la socialdemocracia para el futuro, inspirado en el Manifiesto Laborista con el que la Federación Laborista concurrió a las elecciones de junio de 1977.

Por el contrario, se relata cómo el devenir de unas decepcionantes y oscuras negociaciones hizo que el Partido Laborista no participara en esas primeras elecciones de la era posconstitucional democrática (el 1 de marzo de 1979, con el triunfo de Adolfo Suárez con UCD y el crecimiento, aún en oposición, del PSOE liderado por Felipe González) ni en solitario ni en la coalición electoral "Coalición Democrática", tanto por la "deriva conservadora" de esta (que contó como promotores con Fraga, Areilza, Pastor, Osorio y Lasuén) al constatarse que la Coalición Socialdemócrata difícilmente podía influir integrándose en aquella, como por la situación financiera de "absoluta ruina" del Partido y la Federación Laborista.

$* * * * *$

Con el citado epílogo del segundo capítulo, el capítulo (último) tercero (titulado "Mi experiencia personal") tiene como antesala esa decepción del propio Colomer en el ambiente pre-electoral del 1 de marzo de 1979, que le lleva a criticar sin tapujos "los tejemanejes y miserias de las negociaciones políticas, en donde se ponía de manifiesto lo peor de la condición humana y la floración de todas las ambiciones y codicias, a la vez que la idea del bien común estaba desvanecida" (p. 35). En estos, cifra Antonio Colomer los motivos seguramente más decisivos para abandonar la actividad política y centrarse en la vida universitaria y en las tareas de cooperación solidaria, fundando ya en el año 1978 el Instituto Intercultural para la Autogestión y la Acción Comunal (INAUCO) y, dependiente de ella, creando en 1983 la Revista Iberoamericana de Autogestión y Acción Comunal.

De todas formas, las circunstancias de su vivencia personal han hecho que, por fortuna, el Profesor Colomer pueda legarnos esa última definición de la alternativa electoral laborista pues, al cabo de las décadas, él se encuentra "como último depositario, tanto formal y jurídicamente, como espiritualmente, de esa herencia" (p. 37). En su experiencia, 
comparte con nosotros los interesantes intercambios y amistades que trabó con figuras del movimiento libertario y del movimiento anarcosindicalista, no solo en España, sino de Iberoamérica y del resto de Europa. Con respecto a esto último, conoció y se encontró con Gastón Leval en Valencia y en París (1977 y 1978), traduciendo años después (1994) del francés su obra Práctica del Socialismo Libertario.

En cualquier caso, la interesante y fructífera trayectoria de Antonio Colomer relatada en ese capítulo tercero, tanto en esa breve experiencia de compromiso político como en su dilatada carrera profesional y vocacional en el ámbito universitario, nos permite comprobar que imprimió una huella determinante en la definición de la vertebración ideológica del Partido Laborista, en línea con un socialismo autogestionario (esto es, como socialismo que rechaza la centralización y conceptos burocráticos, enlazando más bien con las tradiciones libertarias, federalistas y descentralizadoras).

El otro eje de influencia en la persona del Profesor Colomer, como queda de manifiesto en las vivencias contenidas en el capítulo tercero, ha sido siempre la América española, Iberoamérica y en especial sus experiencias comunales tan arraigadas, tanto en las culturas amerindias como en las formas cooperativas y mutuales inspiradas en buena medida por los emigrantes europeos, con experiencias como su colaboración con el equipo de la Confederación Latinoamericana de Cooperativas y Mutuales de Trabajadores.

En realidad, no únicamente como Maestro y Profesor en la Universidad, sino ya incluso como estudiante universitario de Derecho en Valencia (o en la Maison du Maroc en la Ciudad Universitaria de París con una agradable convivencia con una "multitud multicultural de estudiantes") a principios de los años 1960 (con anécdotas deliciosas y entrañables que nos narra en ese mismo capítulo tercero), demostró su valía haciendo gala de una vocación universitaria e iberoamericanista con la que ha estado y sigue permanente e infatigablemente comprometido, tanto en su dimensión política y constitucional como en relación con los movimientos comunales y sus valores de apoyo mutuo y reciprocidad.

Y, por descontado, durante la década de los años 1970, Antonio Colomer nos cuenta sus inquietudes, junto con otras personas, por el momento que vivíamos en España y el modo en que íbamos a pasar del franquismo al posfranquismo "con la esperanza de alcanzar una democracia con preocupación social, pero sin riesgos del guerracivilismo, de recuerdos tan trágicos en la historia española” (p. 42). Sobre estas cuestiones, el capítulo nos revvela hechos coherentes como la constitución en 1975 de la Fundación Laboral de Asistencia y Promoción de Empresas (en coherencia con su fidelidad a sus "ideales de transformación social") y, sobre todo, los encuentros con Manuel Fraga y el elegante pero contundente rechazo de Antonio Colomer a unirse al equipo fundador de Alianza Popular para las elecciones de 15 de junio de 1977 (de gran interés es la carta que remitió en tal sentido Colomer a Fraga en el otoño de 1976, reproducida después en la prensa -p. 46-).

En dicha carta, en su crítica a la "tendencia oligárquica, siempre presente en nuestra historia, que ahora se enmascara de democrática", el Profesor Colomer apostaba claramente por el laborismo junto con otros colegas (también universitarios valencianos) 
que representaban "una estampa un tanto quijotesca, en medio de un campo casi desértico, con voces que clamaban casi en el vacío" (p. 48). De todos modos, como parte de esos proyectos sociales, se destaca la aprobación en 1977 de la Editorial "La Hora de Mañana", que funcionó también como revista en Barcelona a partir de 1980 con un grupo de veteranos militantes e intelectuales libertarios, y después como periódico digital, primero en Madrid y en los últimos años desde Valencia, vinculado al INAUCO (www.lahorade.es).

Como elemento destacable, la editorial publicó como primer libro en 1977 el de Vicente Pérez Sábada titulado Una solución de izquierda para España, del que Antonio Colomer (a la sazón Secretario General del Partido Laborista) redactó el prólogo (que figura entre los anexos, lo mismo que el manifiesto laborista, de la obra recensionada), constituyéndose así ese libro en "una de las señas de identidad de la recién constituida Federación Laborista para la cual Vicente y yo redactamos el Manifiesto Laborista, en marzo de 1977, un poco antes de aparecer este libro" (p. 51).

Entre esas señas de identidad prima para Colomer una obsesión sobre la conducta humana que es la coherencia ética entre lo que se piensa y lo que se hace. Y, en el fondo, como relata igualmente el autor, "siempre me he considerado depositario de aquella herencia porque además, irónicamente, a lo largo de estas décadas, aunque el Partido Laborista no volvió a presentarse a nuevas elecciones ni locales, ni autonómicas ni nacionales, recibía en mi domicilio [en Valencia, en donde estaba la sede nacional el partido] alguna notificación como referente de ese Partido Laborista en hibernación, pero existente para alguna estancia burocrática" (p. 57).

Por mor, en última instancia, de esa coherencia ética (además, de nuevo con el laborismo), las últimas páginas del capítulo tercero nos hacen partícipes del modo en que Antonio Colomer rehusó (como sucedió con Fraga) la oportunidad que le ofreció Adolfo Suárez de trabajar con su equipo en el partido Centro Democrático y Social con el que el ex Presidente del Gobierno concurrió a las elecciones de 1982, pese a "tener un trato de cierta intensidad con Adolfo Suárez y me admiró su trayectoria y su coraje quijotesco, también por la lucha por la justicia y enfrentarse a aquellos gigantes, muy reales, que eran el sector más reaccionario de las Fuerzas Armadas, la Iglesia Católica más conservadora y anquilosada en el pasado, y los sectores de las finanzas, lastrados por la sutil usura y la codicia" (p. 57). En suma, el Doctor Colomer no quiso asumir "ninguna candidatura electoral, aunque tuve algunas responsabilidades de gestión y asesoramiento, por un prurito de mi fidelidad laborista".

El capítulo, por último, acaba con dos preciosas anécdotas. La primera, como una ironía de la historia o del destino, relata el Profesor Colomer que el 11 de mayo de 2018 (cuando estaba concluyendo el libro ahora recensionado), recibió en su domicilio de Valencia una carta certificada del Ministerio del Interior (de la Subdirección General de Política Interior y Procesos Electorales) en su calidad de representante del Partido Laborista para adaptarse a la Ley Orgánica 3/2015, de 30 de marzo, de control de la actividad económico-financiera de los partidos políticos, requiriéndole para la adaptación de los 
estatutos del Partido Laborista al contenido mínimo exigido por la nueva legislación, en cuyo defecto se declararía judicialmente la extinción del partido... tratándose pues “de una muerte burocrática anunciada, casi medio siglo después de que se creara el Partido Laborista" (p. 59). La segunda es haber rescatado el manuscrito del "Himno laborista" (transcrito en la p. 60) que redactó su gran poeta y amigo Antonio Carlos González, un "texto extraviado [que] ha sido reencontrado y es la mejor forma de cerrar estos recuerdos y reflexiones".

$* * * * *$

Llegados a este punto, no me resta sino enfatizar dos aspectos de la obra reseñada del Profesor Colomer Viadel que, a mi modo de ver, la convierten en texto de referencia y consulta insoslayables para comprender, no únicamente la apuesta del laborismo español en palabras de uno de sus máximos protagonistas, sino igualmente y de manera más amplia ese período fundamental de la reciente historia española que es nuestra transición a la democracia que condujo a la adopción de la Constitución vigente de 1978.

El primero, en el plano estricto de la excelencia investigadora, reside en ofrecer un texto redactado magistralmente por su autor (con una ingente y sólida obra que es referente ineludible del constitucionalismo español y comparado, especialmente iberoamericano), con soporte en unos testimonios y unas fuentes que responden en buena medida a la autoría del propio Doctor Colomer. En cuanto al segundo, tiene que ver con esa imbricación entre la vocación universitaria y la transferencia de conocimiento a la sociedad con coherencia ética, entre lo universitario y lo político.

Tal como lo califica Carlos Díaz en un texto publicado recientemente (20 de mayo de 2020) en la web del Instituto Emmanuel Mounier, Antonio Colomer Viadel es "un ejemplar único del laborismo libertario", con una "magna aportación al bien común en España y en Latinoamérica"; como "prócer de la elegancia cultural, de la ponderación y de la capacidad dialógica, Colomer ama kantianamente a cada persona en la humanidad, y a la humanidad en cada persona".

Con esto, casi sobran todas las palabras: la actitud quijotesca de Antonio Colomer, que al tiempo asume esos tintes weberianos según los cuales la persona no habría conseguido lo posible si repetidamente no hubiera intentado lo imposible (acompañada de esa misma vocación de Max Weber de imbricación de la Universidad y la Política, particularmente del papel del jurista universitario en la transformación de la empresa política) nos animan (también como maestro y amigo de quien suscribe) a seguir su fecunda tarea universitaria y su actitud coherente ante la vida para conseguir (como dice nuestro Preámbulo constitucional) un orden económico y social justo. De esto va, a fin de cuentas, el libro que recensionamos, confiando en que llegue al máximo número de personas. 